https://doi.org/10.15407/ujpe65.2.162

O.V. MELNICHUK, ${ }^{1}$ L.YU. MELNICHUK, ${ }^{1}$ N.O. KORSUNSKA, ${ }^{2}$ L.YU. KHOMENKOVA, ${ }^{2,3}$ E.F. VENGER, ${ }^{2}$ I.V. VENGER ${ }^{2}$

${ }^{1}$ Mykola Gogol State University of Nizhyn

(2, Grafs'ka Str., Nizhyn 16600,Ukraine; e-mail: mov310310@gmail.com)

2 V.E. Lashkaryov Institute of Semiconductor Physics, Nat. Acad. of Sci. of Ukraine

(41, Prosp. Nauky, Kyiv 03028, Ukraine)

3 National University of Kyiv-Mohyla Academy

(2, G. Skovorody Str., Kyiv 04070, Ukraine)

\title{
PHONON-POLARITON EXCITATIONS IN MgZnO/6H-SiC STRUCTURES
}

\begin{abstract}
Specular infrared reflection spectra in the range of "residual rays" of the film and the substrate and in the case of the $E \perp c$ orientation of the electric field have been simulated for the first time for thin $\mathrm{Mg}_{x} \mathrm{Zn}_{1-x} \mathrm{O}$ films deposited on optically anisotropic 6H-SiC substrates. The simulation was carried out making use of self-consistent parameters obtained earlier for magnesium oxide, zinc oxide, and silicon carbide single crystals. The film thickness and the $M g$ content $x$ in the film are demonstrated to considerably distort the reflection spectra and to change the reflectivity of the $\mathrm{Mg}_{x} \mathrm{Zn}_{1-x} \mathrm{O} / 6 \mathrm{H}$-SiC structure. Using the Kramers-Kronig relation, the spectral intervals, where the reflectivity is sensitive to the film thickness and to the doping levels of the film and the substrate, are determined. The main attention is paid to analyze results obtained for $x=0$.2. The existence of surface polaritons in such structures is theoretically demonstrated for the first time, and the attenuated total reflectance surface $I(\nu) / I_{0}(\nu)$ is plotted as a three-dimensional representation of the structure transmittance dependence on the radiation frequency and the incidence angle. A possibility to study the resonant interaction of optical phonons with plasmons in the film and the substrate is demonstrated.
\end{abstract}

Ke ywords: surface polaritons, IR spectroscopy, zinc oxide, magnesium oxide, $\mathrm{Mg}_{x} \mathrm{Zn}_{1-x} \mathrm{O}$, silicon carbide.

\section{Introduction}

Owing to their unique properties (high photosensitivity, high photo- and cathodoluminescence yields, pyro- and piezoeffects, and so forth), $\mathrm{Mg}_{x} \mathrm{Zn}_{1-x} \mathrm{O}$ films belong to the materials that form a basis for a wide variety of optoelectronic devices operating on bulk and surface waves [1-6]. The advantages of those devices consist in their miniature size, a high efficiency within a wide frequency interval, and the ability to be integrated with other microelectronic elements [5-9]. This is so because the devices that are based on structures containing zinc oxide and magnesium oxide have a number of considerable advantages.

As a rule, $\mathrm{Mg}_{x} \mathrm{Zn}_{1-x} \mathrm{O}$ solid solution films are created by combining the corresponding oxides - zinc

(C) O.V. MELNICHUK, L.YU. MELNICHUK,

N.O. KORSUNSKA, L.YU. KHOMENKOVA,

E.F. VENGER, I.V. VENGER, 2020

162 oxide $(\mathrm{ZnO})$ and magnesium oxide $(\mathrm{MgO})$ - taken in definite concentrations. The both oxides belong to wide-band semiconductors of the $\mathrm{A}^{2} \mathrm{~B}^{6}$ type.

Zinc oxide is known to have a hexagonal crystalline structure belonging to the $C_{6 v}^{4}\left(P 6_{3} m c\right)$ group with the lattice parameters $a=3.2495 \AA$ and $c=$ $=5.2069 \AA$, a bandgap of about $3.36 \mathrm{eV}$, and an exciton binding energy of $60 \mathrm{meV}$. Zinc oxide is characterized by high radiation, chemical and thermal stabilities. Currently, this semiconductor is already applied rather widely in acoustics, opto- and nanoelectronics [10-13]. Zinc oxide is particularly suitable for the manufacture of transparent film electrodes in solar cells [14], creation of detectors and filters in the ultraviolet range, and laser generation at room temperature $[10,11]$. Furthermore, $\mathrm{ZnO}$ is widely used to manufacture gas sensors, light-emitting diodes, and varistors, as well as photocatalysts for the water and air purifications [14]. It is known that the doping of

ISSN 2071-0194. Ukr. J. Phys. 2020. Vol. 65, No. 2 
zinc oxide with various elements allows its functional properties to be to extended [15]. For example, the elements belonging to the second group and located higher in the Mendeleev table of elements - e.g., Mg [16] - should be used in order to increase the $\mathrm{ZnO}$ bandgap energy $E_{g}$, and the elements located below e.g., Cd [17] - in order to reduce $E_{g}$.

Magnesium oxide is one of the most wide-spread natural minerals. It crystallizes in the rocky structures of the Earth under arbitrary pressure and temperature conditions [18]. MgO crystals are transparent. They are not fire-hazardous and highly explosive. They have a high melting point of $2800^{\circ} \mathrm{C}$ and, therefore, are widely used as a substrate material for thin-film growing processes in modern microelectronic and optoelectronic devices [18]. $\mathrm{MgO}$ is practically insoluble in water, but can be solved in hydrochloric, sulfuric, and acetic acids. $\mathrm{MgO}$ belongs to the Fm $3 m$ crystalline group and has a cubic structure with the cell parameter $a=4.216 \AA$. In comparison with $\mathrm{ZnO}, \mathrm{MgO}$ has a much wider band gap (from 7.8 to $8.2 \mathrm{eV}$ ) and is sometimes considered as an insulator.

Theoretically, the probability for the $\mathrm{Mg}_{x} \mathrm{Zn}_{1-x} \mathrm{O}$ solid solutions with various $\mathrm{Mg}$ contents to be formed is high, because no charge compensation is required when a magnesium atom is incorporated into the zinc site of the crystal lattice. In this case, as was indicated above, the increase of the $\mathrm{MgO}$ content is accompanied by an increase of the band gap in comparison with the band gap in $\mathrm{ZnO}$. It is a possibility to change the optical and electrophysical properties of ternary $\mathrm{Mg}_{x} \mathrm{Zn}_{1-x} \mathrm{O}$ compounds that extends the limits of their application, since the operating frequencies of lasers, LEDs, and photodetectors can be shifted toward far ultraviolet. This opportunity was first described in works by Kawasaki et al. $[16,17]$. Those materials are also promising for the creation of anti-reflection layers in large-area solar cells [19-26].

Depending on the relative $\mathrm{Mg}$ and $\mathrm{Zn}$ concentrations, the $\mathrm{Mg}_{x} \mathrm{Zn}_{1-x} \mathrm{O}$ compounds can have either the hexagonal (the wurtzite type) or cubic crystalline structure. For example, our previous studies of $\mathrm{Mg}_{x} \mathrm{Zn}_{1-x} \mathrm{O}$ thick layers and ceramic specimens prepared from a mixture of oxides using the solidphase reaction method at high temperatures showed that a homogeneous solid solution with the hexagonal structure can be obtained, if the magnesium ox- ide content does not exceed a value of about $20 \%$ $(x=0.2)$. In this case, the band gap increases to $3.7 \mathrm{eV}[27,28]$. At $x>0.2$, the additional formation of the $\mathrm{MgO}$ phase with cubic structure takes place. Therefore, the study of $\mathrm{Mg}_{x} \mathrm{Zn}_{1-x} \mathrm{O}$ compounds with $0<x<0.2$ seems to be very attractive, because those materials preserve their hexagonal crystalline structure and demonstrate anisotropic optical properties in the IR spectral interval.

As concerning the application of $\mathrm{Mg}_{x} \mathrm{Zn}_{1-x} \mathrm{O}$ materials, their films deposited on various substrates (such as $\mathrm{Si}, \mathrm{SiO}_{2}, \mathrm{Al}_{2} \mathrm{O}_{3}, 6 \mathrm{H}-\mathrm{SiC}$, and others) are the most promising, because they have a much lower cost as compared with that of single crystals.

It should be noted that, in some papers [29-31], it was reported about the fabrication of thin films of $\mathrm{Mg}_{x} \mathrm{Zn}_{1-x} \mathrm{O}$ solid solutions with $x=0.24-0.30$ and the hexagonal structure. If $x$ was increased to 0.4 , the cubic $\mathrm{MgO}$ phase was also formed. At the same time, there are no data in the literature concerning the properties of thin $\mathrm{Mg}_{x} \mathrm{Zn}_{1-x} \mathrm{O}$ films with higher magnesium contents.

Among various substrates that can be used for the fabrication of $\mathrm{Mg}_{x} \mathrm{Zn}_{1-x} \mathrm{O}$ films, the special attention is paid to silicon carbide ( $\mathrm{SiC}$ ) ones. This is the only binary compound of silicon and carbon that exists in the solid phase. The chemical binding of silicon and carbon in the silicon carbide lattice is characterized by a strong ion-covalent bond, which provides this compound with uncommon physicochemical properties [32-34]. Analogously to $\mathrm{ZnO}$ single crystals, SiC$6 \mathrm{H}$ ones belong to the $C_{6 \mathrm{~V}}^{4}\left(P 6_{3} m c\right)$ space group, but, unlike the former, they are characterized by a strong anisotropy of the properties of their plasmon subsystem [33].

Currently, silicon carbide is a basis for the creation of a number of semiconductor devices: fluorescent indicators, nuclear radiation meters, photodetectors, high-temperature diodes, strain gauges, thermistors, field transistors with $p-n$ junction, and others $[32,33]$. Such a wide practical application of silicon carbide single crystals is associated with a possibility to vary their electrical, optical, luminescent, and photoelectric properties, their high stability to the action of external factors, and a unique combination of physical and chemical properties such as high thermal, mechanical, radiation, and chemical resistances. By its hardness, silicon carbide is inferior to only diamond and boron carbide. At temperatures up 
to $400{ }^{\circ} \mathrm{C}$, it almost does not interact with any other known etchant for semiconductor materials [32, 33].

Common to the materials concerned - these are $\mathrm{ZnO}, \mathrm{MgO}$, and $\mathrm{SiC}-6 \mathrm{H}$ - is the range of "residual rays" occupying the spectral interval from 400 to $1000 \mathrm{~cm}^{-1}$ and allowing their practical application to be extended. It should be noted that the properties of each of indicated single crystals have been thoroughly studied by us earlier [25, 33, 35].

Recently, $\mathrm{ZnO}$ thin films deposited onto various substrates have been studied both theoretically and experimentally [36-38]. However, we do not know publications concerning the study of $\mathrm{MgZnO}$ films with various chemical compositions and electron concentrations that are located on $6 \mathrm{H}-\mathrm{SiC}$ dielectric substrates, which were carried out making use of IR reflection spectroscopy and the attenuated total reflection (ATR) method in the range of "residual rays" of the film and the substrate, and for the radiation orientation $E \perp c$. Therefore, the aim of this work was to model the external IR reflection spectra for various doping levels of the film and the substrate, and to determine the frequency intervals in which the excitation of surface phonon and plasmon-phonon polaritons in the films of ternary $\mathrm{Mg}_{x} \mathrm{Zn}_{1-x} \mathrm{O}$ compounds on optically isotropic $6 \mathrm{H}-\mathrm{SiC}$ substrates is possible.

\section{IR Spectroscopy Methods for the Study of MgZnO/6H-SiC Structures}

The external IR reflection and surface polariton (SP) spectroscopy methods are known to belong to the group of non-destructive methods for studying the optical and electrophysical properties of thin semiconductor and dielectric oxide films in order to control their quality and structural perfection [19]. The both methods provide not only information about the physical and chemical properties of the film, but also about the substrate parameters and the quality of the substrate surface treatment.

A detailed analysis of the technique used for the research of the optical and electrophysical characteristics of $\mathrm{ZnO}$ films deposited onto semiconductor and dielectric substrates - $\mathrm{Si}, \mathrm{SiO}_{2}$, and others - making use of external IR reflection spectroscopy and considering the phonon and plasmon-phonon interactions in the film and the substrate was done in works $[36,38]$.

As for the ATR method, its essence consists in the following [19]. Under the condition of total inter- nal reflection, a beam of IR radiation can penetrate from an optically more dense medium that is transparent in the IR region into a medium that is optically less dense only to a depth that is comparable with the incident IR wavelength. If the optically less dense medium absorbs, then the intensity of light penetrating into this medium becomes weaker, and the reflection is not total. One should remember that the investigated medium is characterized by the strong absorption in the IR range. Under those conditions, spectral devices will register the ATR spectrum.

When the electromagnetic radiation interacts with various types of oscillations (phonons, plasmons, and others), the excitation and propagation of surface electromagnetic waves, i.e. surface polaritons, occur in the range of "residual rays" of uniaxial crystals and structures based on them. Surface polaritons are surface quasiparticles corresponding to oscillations of a mixed electromagnetic-mechanical character. The maximum of their field amplitude takes place at the surface of a solid, and the field amplitude itself decreases exponentially in both directions from the interface. The interaction of surface optical phonons with surface plasma oscillations of free charge carriers leads to the excitation of mixed surface plasmonphonon polaritons (SPPPs), whose oscillation spectrum undergoes the maximum reconstruction, if the plasma frequency $\nu_{p}$ is close to the longitudinaloptical-phonon frequency $\nu_{L}$. Furthermore, the analytical capabilities of SP spectroscopy drastically increase, if the frequencies of optical phonons in the film fall within the frequency interval of SPs in the substrate. The corresponding resonance gives rise to the split and the shift of the SP spectrum in the substrate. In this case, the experimental data make it possible to determine the dielectric constants of the film and the substrate, find the film thickness, and characterize the structure itself [39].

\section{Theory and Analysis of Spectra for the $\mathrm{MgZnO} / 6 \mathrm{H}-\mathrm{SiC}$ Structure}

Nowadays, there are a number of scientific works devoted to the study of hexagonal single crystals of electron silicon carbide (the $6 \mathrm{H}$ polytype) with the help of non-destructive IR spectroscopy and surface polariton methods [19, 25, 33, 34, 40-43]. Experimental reflection spectra from the $\mathrm{SiC}-6 \mathrm{H}$ surface with a high electron concentration $\left(>10^{18} \mathrm{~cm}^{-3}\right)$ were studied for

ISSN 2071-0194. Ukr. J. Phys. 2020. Vol. 65, No. 2 
the first time in our work [25]. In works [19, 25,33, 4043 , we also studied the influence of the crystal lattice and the effective electron mass anisotropy, as well as the phonon, $\gamma_{f}$, and plasmon, $\gamma_{p}$, damping coefficients, on the reflection coefficient from the surface of SiC-6H single crystals in the infrared spectral interval.

In work [44], the optical characteristics of thin films of ternary $\mathrm{Mg}_{x} \mathrm{Zn}_{1-x} \mathrm{O}$ compounds on $\mathrm{Al}_{2} \mathrm{O}_{3}$ dielectric substrates in the range of the film and substrate "residual rays" were obtained using the method of external reflection IR spectroscopy. It was shown that the changes in the film thickness and the $\mathrm{Mg}$ content substantially distort the reflection spectrum in the range of the film and substrate "residual rays" and reduce the reflectance. The simulation of IR spectra in the $E \perp c$ orientation geometry allowed us to determine the static dielectric constants for $\mathrm{Mg}_{x} \mathrm{Zn}_{1-x} \mathrm{O}$ compounds with various $x$-values. It was found that the $\mathrm{Mg}_{x} \mathrm{Zn}_{1-x} \mathrm{O} / \mathrm{Al}_{2} \mathrm{O}_{3}$ structures in the $E \perp c$ orientation can be reproduced well, if self-consistent parameters are used for magnesium oxide, zinc oxide, and leucosapphire single crystals. This result confirms the promising potential of non-destructive IR spectroscopy for finding the optical characteristics of ternary-compound films and their textural level.

Theoretical researches of IR reflection spectra from the $\mathrm{MgZnO}$ film deposited onto the semiinfinite $6 \mathrm{H}$ $\mathrm{SiC}$ semiconductor substrate in the range of "residual rays" of zinc oxide, magnesium oxide, and silicon carbide (the $6 \mathrm{H}$ polytype) were carried out with the help of mathematical expressions derived in works $[35,35,43]$. In the case $E \perp c$, those expressions involve the interaction of IR radiation with the phonon and plasmon subsystems in the MgZnO film on the semiinfinite $\mathrm{SiC}-6 \mathrm{H}$ substrate.

The calculation was carried out in the framework of the dielectric constant model with the additive contributions of active optical phonons and plasmons [19, 42, 43],

$$
\begin{aligned}
& \varepsilon_{j}(\nu)=\varepsilon_{1 j}(\nu)+i \varepsilon_{2 j}(\nu)= \\
& =\varepsilon_{\infty j}+\frac{\varepsilon_{\infty j}\left(\nu_{L j}^{2}-\nu_{T j}^{2}\right)}{\nu_{T j}^{2}-\nu^{2}-i \nu \gamma_{f j}}-\frac{\nu_{p j}^{2} \varepsilon_{\infty j}}{\nu\left(\nu+i \gamma_{p j}\right)},
\end{aligned}
$$

where $\nu_{L}$ and $\nu_{T}$ are the frequencies of the longitudinal and transverse optical phonons, respectively; $\gamma_{f}$ is the optical phonon damping coefficient; $\gamma_{p}$ and

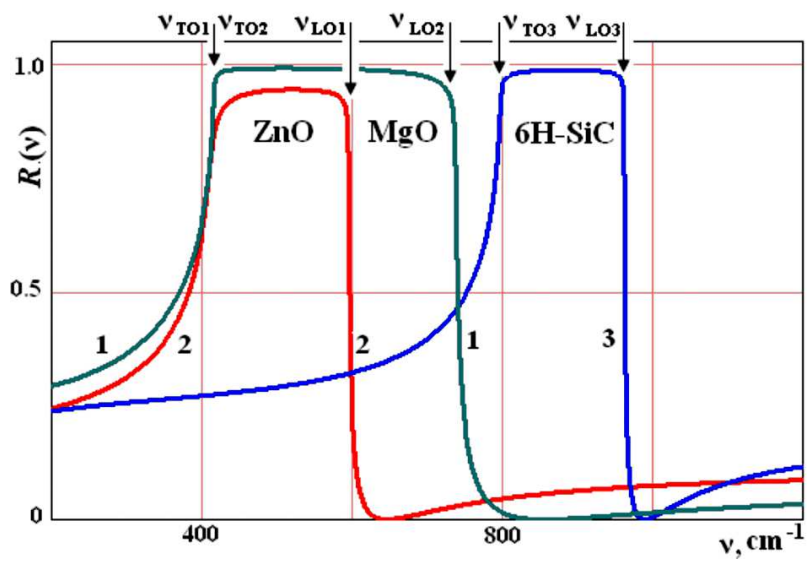

Fig. 1. Calculated IR reflectance spectra $R(\nu)$ for $\operatorname{MgO}(1)$, $\mathrm{ZnO}(2)$, and $6 \mathrm{H}-\mathrm{SiC}(3)$ single crystals at the orientation $E \perp c$

$\nu_{p}$ are the damping coefficient and the frequency of the plasma resonance, respectively. The external IR reflection spectra were calculated making no allowance for the absorption [19]. The reflection coefficient is considered as $R(\nu, \varphi)=I(\nu, \varphi) / I_{0}(\nu, \varphi)$, where $I_{0}(\nu, \varphi)$ and $I(\nu, \varphi)$ are the intensity of incident and reflected irradiation, respectively. For the simulation of IR spectra, the mathematical editor MathCAD was used.

In Fig. 1, we show the IR reflectance spectra of magnesium oxide (curve 1), zinc oxide (curve 2), and silicon carbide (curve 3) single crystals which were calculated for the orientation $E \perp c$ with the regard for the results of works $[25,33,35]$. Mathematical expressions obtained in work [19] in the framework of the one-oscillator model are used to simulate the IR reflectance spectra. The corresponding self-consistent oscillator parameters for those single crystals are listed in Table 1 . The ranges of "residual rays" for the examined single crystals are located between the frequency of transverse optical phonons in magnesium and zinc oxides $\left(\nu_{T O 1}, \nu_{T O 2}\right)$ and the fre-

Table 1. Mutually consistent bulk parameters of $\mathrm{ZnO}, 6 \mathrm{H}-\mathrm{SiC}$, and $\mathrm{MgO}$ single crystals at $T=293 \mathrm{~K}[25,33,35])$

\begin{tabular}{|l|l|l|c|c|}
\hline \multicolumn{1}{|c|}{ Parameter } & $\varepsilon_{0}$ & $\varepsilon_{\infty}$ & $\nu_{T}, \mathrm{~cm}^{-1}$ & $\nu_{L}, \mathrm{~cm}^{-1}$ \\
\hline $\mathrm{ZnO}(E \perp c)$ & 8.1 & 3.95 & 412 & 591 \\
$6 \mathrm{H}-\mathrm{SiC}(E \perp c)$ & 9.66 & 6.52 & 797 & 961 \\
$\mathrm{MgO}(E \perp c)$ & 2.98 & 9.39 & 416 & 738 \\
\hline
\end{tabular}


Table 2. Phonon subsystem parameters for $\mathrm{Mg}_{0.2} \mathbf{Z n}_{0.8} \mathrm{O}$ and $\mathbf{6 H}-\mathrm{SiC}$

\begin{tabular}{|c|c|c|c|c|c|c|c|c|c|c|c|}
\hline Sample & $\varepsilon_{\infty}$ & $\varepsilon_{0}$ & $\begin{array}{l}\nu_{T O 1} \\
\mathrm{~cm}^{-1}\end{array}$ & $\Delta S_{1}$ & $\begin{array}{c}\gamma_{f 1}, \\
\mathrm{~cm}^{-1}\end{array}$ & $\begin{array}{l}\nu_{\mathrm{TO} 2} \\
\mathrm{~cm}^{-1}\end{array}$ & $\Delta S_{2}$ & $\begin{array}{c}\gamma_{f 2}, \\
\mathrm{~cm}^{-1}\end{array}$ & $\begin{array}{l}\nu_{T O 3} \\
\mathrm{~cm}^{-1}\end{array}$ & $\Delta S_{2}$ & $\begin{array}{c}\gamma_{f 3}, \\
\mathrm{~cm}^{-1}\end{array}$ \\
\hline $\mathrm{Mg}_{0.2} \mathrm{Zn}_{0.8} \mathrm{O}$ & 3.51 & 8.0 & 414.1 & 0.69 & 13.8 & 551.8 & 1.8 & 17.7 & 605 & 2.0 & 70.7 \\
\hline $6 \mathrm{H}-\mathrm{SiC}$ & 6.52 & 9.66 & 797 & 3.14 & 3.0 & - & - & - & - & - & - \\
\hline
\end{tabular}

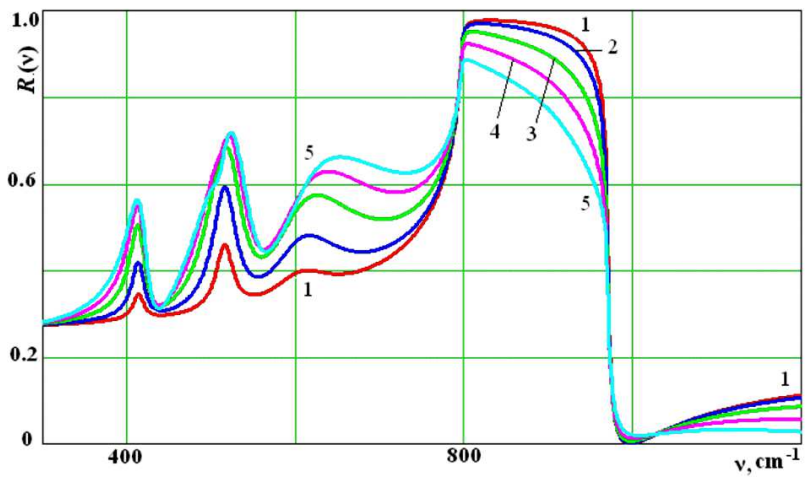

Fig. 2. Theoretical reflectance spectra $R(\nu)$ for the $\mathrm{Mg}_{x} \mathrm{Zn}_{1-x} \mathrm{O} / 6 \mathrm{H}-\mathrm{SiC}$ structure with $x=0.2$ and various $d_{\text {film }}=0.1$ (1), 0.25 (2), 0.5 (3), 0.75 (4), and $1.0 \mu \mathrm{m}(5)$

quency of longitudinal optical phonons in silicon carbide (the $6 \mathrm{H}$ polytype) $\left(\nu_{L O 3}\right)$. The reflectance maxima equal 0.99 (curve 1), 0.94 (curve 2), and 0.98 (curve 3). Both $\mathrm{ZnO}$ and $6 \mathrm{H}-\mathrm{SiC}$ single crystals have the wurtzite crystalline structure and belong to the same spatial group $C_{6 \mathrm{~V}}^{4}\left(\mathrm{P}_{3} m c\right)$.

$\mathrm{MgO}$ has the crystalline structure of sodium chloride. A more detailed analysis of the procedure aimed at obtaining self-consistent parameters of the oneoscillator model for $\mathrm{ZnO}$ and $6 \mathrm{H}-\mathrm{SiC}$ was done in our works $[19,25,33]$. In work [33], we showed that $\mathrm{ZnO}$ is characterized by a significant anisotropy of properties for the phonon subsystem and a weak anisotropy of properties for the plasmon one, whereas silicon carbide (the $6 \mathrm{H}$ polytype) is characterized by a weak anisotropy of properties for the phonon subsystem and a strong anisotropy of properties for the plasmon one [25]. Therefore, those single crystals are good model objects that are convenient for studying the anisotropy of optical and electrophysical properties using the IR reflection and surface polariton spectroscopy methods in the presence of coupling between long-wave optical lattice vibrations and the electron plasma in semiconductors.
From Fig. 1, one can see that the range of "residual rays" for $6 \mathrm{H}-\mathrm{SiC}$ is located within an interval of 800 $1000 \mathrm{~cm}^{-1}$ and does not overlap with the intervals $\left(\nu_{T O 1}, \nu_{L O 1}\right)$ for $\mathrm{ZnO}$ single crystals and $\left(\nu_{T O 2}, \nu_{L O 2}\right)$ for $\mathrm{MgO}$ ones. However, the range of "residual rays" for $\mathrm{ZnO}$ is located between the frequencies $\nu_{\mathrm{TO}}$ and $\nu_{\mathrm{LO} 2}$ for $\mathrm{MgO}$, which has to be taken into account when simulating and analyzing the $\mathrm{Mg}_{x} \mathrm{Zn}_{1-x} \mathrm{O} / 6 \mathrm{H}-$ SiC heterostructure.

Figure 2 demonstrates how the dependence $R(\nu)$ for the undoped $\mathrm{Mg}_{x} \mathrm{Zn}_{1-x} \mathrm{O} / 6 \mathrm{H}-\mathrm{SiC}$ structure changes with the $\mathrm{Mg}_{x} \mathrm{Zn}_{1-x} \mathrm{O}$ film thickness. Curves 1 to 5 correspond to the thickness values from 0.1 to $1.0 \mu \mathrm{m}$. The calculation was carried out using the parameters of phonon subsystems in the film and the substrate that are indicated in Table 2. The plasmon subsystem was given by the constant parameter values $\gamma_{f 6 \mathrm{H}-\mathrm{SiC}}=3 \mathrm{~cm}^{-1}$ and $\nu_{p \perp}=\gamma_{p \perp}=$ $=1 \mathrm{~cm}^{-1}$. The simulation was carried out using the Kramers-Kronig relations and the data obtained by us [45] and presented in Table 2. The value of the static dielectric permittivity was determined by us using the Lyddane-Sachs-Teller relation [44]. The presented results are in good agreement with the data obtained in works $[25,33,35]$.

As one can see from Fig. 2, the growth of the film thickness from 0.1 to $1 \mu \mathrm{m}$ leads to a significant increase of $R(\nu)$ in the whole range of "residual rays" for $\mathrm{Mg}_{x} \mathrm{Zn}_{1-x} \mathrm{O}$ and a reduction of the reflectance $R(\nu)$ in the range of "residual rays" for the $6 \mathrm{H}-\mathrm{SiC}$ substrate. In a vicinity of the transverse optical phonon frequency $\left(412 \mathrm{~cm}^{-1}\right)$ in $\mathrm{ZnO}$, there is a maximum corresponding to a frequency of $416 \mathrm{~cm}^{-1}$ (curve 1), which moves toward a lower frequency of $412 \mathrm{~cm}^{-1}$ (curve 5), when the film thickness increases to $1 \mu \mathrm{m}$. At a frequency of $520 \mathrm{~cm}^{-1}$, the value of $R(\nu)$ changes from 0.44 at $d_{\text {film }}=0.1 \mu \mathrm{m}$ to 0.72 at $d_{\text {film }}=1 \mu \mathrm{m}$. At a frequency of $412 \mathrm{~cm}^{-1}$, $R(\nu)$ changes from 0.34 at $d_{\text {film }}=0.1 \mu \mathrm{m}$ to 0.56 at $d_{\text {film }}=1 \mu \mathrm{m}$. However, in the range of $500-$

ISSN 2071-0194. Ukr. J. Phys. 2020. Vol. 65, No. 2 
$550 \mathrm{~cm}^{-1}$, the growth of the film thickness is accompanied by a shift of the spectral maximum into the high-frequency region by $40 \mathrm{~cm}^{-1}$. Substantial changes in the spectrum take place in the interval from 600 to $720 \mathrm{~cm}^{-1}$, where $R(\nu)$ increases by $22 \%$, which is accompanied by a shift of the maximum frequency from 615 to $654 \mathrm{~cm}^{-1}$. In the range of "residual rays" for the $6 \mathrm{H}-\mathrm{SiC}$ substrate, a reduction of $R(\nu)$ by $20 \%$ was obtained at a frequency of $900 \mathrm{~cm}^{-1}$, when the film thickness increased to $1 \mu \mathrm{m}$, which was caused by the influence of the phonon subsystem on the reflectance spectrum of the $\mathrm{Mg}_{x} \mathrm{Zn}_{1-x} \mathrm{O} / 6 \mathrm{H}-\mathrm{SiC}$ structure. The maximum sensitivity of the reflectance $R(\nu)$ to the film thickness growth was observed in the low-frequency spectral interval. In the interval from 400 to $600 \mathrm{~cm}^{-1}$, a reflectance increases by $22 \%$.

Figure 3 illustrates the shape dependence of the IR reflectance spectra on the free charge carrier concentration in $\mathrm{Mg}_{x} \mathrm{Zn}_{1-x} \mathrm{O}$ films $500 \mathrm{~nm}$ thick. Curves 1 to 5 were calculated for $\gamma_{p \perp}=\nu_{p \perp}$ varying from 100 to $1000 \mathrm{~cm}^{-1}$. One can see that the reflectance spectra $R(\nu)$ undergo the most significant changes in the intervals of $300-400 \mathrm{~cm}^{-1}$ and $900-980 \mathrm{~cm}^{-1}$, where $R(\nu)$ decreases from 0.96 to 0.5 , and in the interval of $1000-1100 \mathrm{~cm}^{-1}$, where $R(\nu)$ increases from 0 to 0.38 .

The $R(\nu)$ maxima are located at frequencies of $413 \mathrm{~cm}^{-1}(R(\nu)=0.49), 516 \mathrm{~cm}^{-1}(R(\nu)=0.68)$, and $630 \mathrm{~cm}^{-1}(R(\nu)=0.57)$. However, irrespective of the film doping level, the external reflection coefficient $R(\nu)$ decreases, as the frequency grows in the high-frequency section of the spectrum. Curves 1 to 5 for $R(\nu)$ were calculated for the parameters of the phonon subsystem in the $\mathrm{Mg}_{x} \mathrm{Zn}_{1-x} \mathrm{O}$ film and the $6 \mathrm{H}-\mathrm{SiC}$ substrate that are quoted in Table 2. The parameters $\nu_{p}$ and $\gamma_{p}\left(\nu_{p}=\gamma_{p}\right)$ of the plasmon subsystem in $\mathrm{Mg}_{x} \mathrm{Zn}_{1-x} \mathrm{O}$ were varied from 100 to $1000 \mathrm{~cm}^{-1}$, which corresponds to the concentration change from $10^{16}$ to $10^{19} \mathrm{~cm}^{-3}$, the mobility change from 90 to $200 \mathrm{~cm}^{2} \mathrm{~V}^{-1} \mathrm{~s}^{-1}$, and the conductivity change from 100 to $410 \Omega^{-1} \mathrm{~cm}^{-1}$. At a frequency of $970 \mathrm{~cm}^{-2}$, the $R(\nu)$ value is constant $(R(\nu) \approx 0.5)$ and does not change, when the film and the substrate undergo a doping.

As one can see from Fig. 3, the presence of free charge carriers (electrons) with the concentrations $n_{0}=10^{16} \div 10^{19} \mathrm{~cm}^{-3}$ in the $\mathrm{Mg}_{x} \mathrm{Zn}_{1-x} \mathrm{O}$ films substantially deforms the reflectance spectrum in the in-

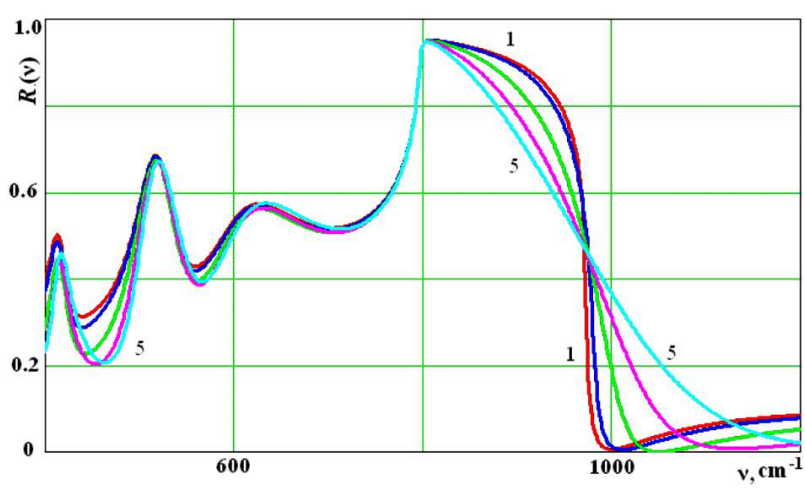

Fig. 3. Theoretical reflectance spectra $R(\nu)$ for the $\mathrm{Mg}_{x} \mathrm{Zn}_{1-x} \mathrm{O} / 6 \mathrm{H}-\mathrm{SiC} \quad$ structure with $d_{\text {film }}=500 \mathrm{~nm}$, $\gamma_{f 6 \mathrm{H}-\mathrm{SiC}}=3 \mathrm{~cm}^{-1}$, and various $\nu_{p 6 \mathrm{H}-\mathrm{SiC}}=\gamma_{p 6 \mathrm{H}-\mathrm{SiC}}=$ $=100(1), 250$ (2), 500 (3), 750 (4), and $1000 \mathrm{~cm}^{-1}$ (5)

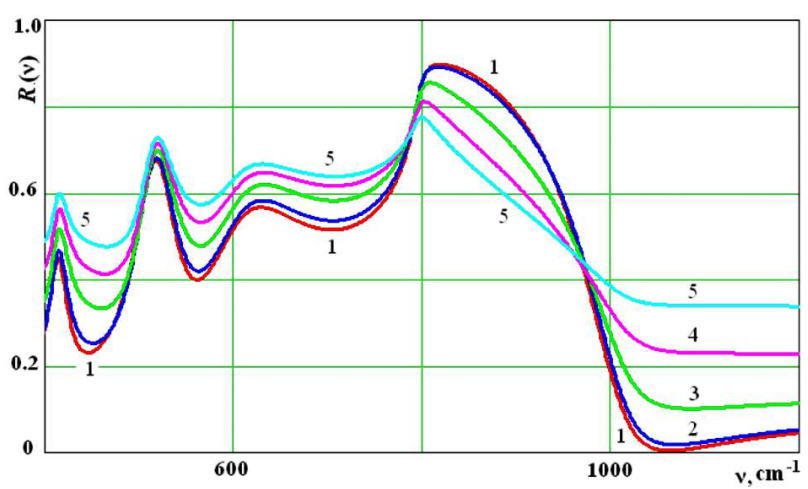

Fig. 4. Reflectance spectra $R(\nu)$ for the $\mathrm{Mg}_{x} \mathrm{Zn}_{1-x} \mathrm{O} / 6 \mathrm{H}-$ $\mathrm{SiC}$ structure with $d_{\text {film }}=500 \mathrm{~nm}$. Substrate parameters: $\gamma_{f 6 \mathrm{H}-\mathrm{SiC}}=12 \mathrm{~cm}^{-1}, \nu_{p 6 \mathrm{H}-\mathrm{SiC}}=550 \mathrm{~cm}^{-1}$, and $\gamma_{p 6 \mathrm{H}-\mathrm{SiC}}=$ $620 \mathrm{~cm}^{-1} . \mathrm{Mg}_{x} \mathrm{Zn}_{1-x} \mathrm{O}$ film parameters: $\nu_{p}=\gamma_{p}=100$ (1), 250 (2), 500 (3), 750 (4), and $1000 \mathrm{~cm}^{-1}$ (5)

tervals $420-480 \mathrm{~cm}^{-1}$ and $800-1000 \mathrm{~cm}^{-1}$. This is a result of the interaction of the phonon and plasmon subsystems in the $\mathrm{Mg}_{x} \mathrm{Zn}_{1-x} \mathrm{O}$ film with the phonon and plasmon subsystems in the $6 \mathrm{H}-\mathrm{SiC}$ substrate.

In Fig. 4, the $R(\nu)$ spectra are shown for various $\nu_{p}$ (this parameter is related to the free charge carrier concentration) in the $\mathrm{Mg}_{x} \mathrm{Zn}_{1-x} \mathrm{O}$ film deposited onto the optically isotropic doped $6 \mathrm{H}-\mathrm{SiC}$ substrate, provided that the parameters of the phonon subsystems in the film and the substrate are constant and correspond to the values given in Tables 1 and 2 . The simulation was carried out for $\nu_{p 6 \mathrm{H}-\mathrm{SiC} \perp}=550 \mathrm{~cm}^{-1}$ and $\gamma_{p 6 \mathrm{H}-\mathrm{SiC} \perp}=620 \mathrm{~cm}^{-1}$, which corresponds to the concentration of free charge carriers in the $6 \mathrm{H}$ SiC substrate $n_{0}=5 \times 10^{18} \mathrm{~cm}^{-3}$ and their mobility $\mu=370 \mathrm{~cm}^{2} \mathrm{~V}^{-1} \mathrm{~s}^{-1}$. The figure demonstrates 


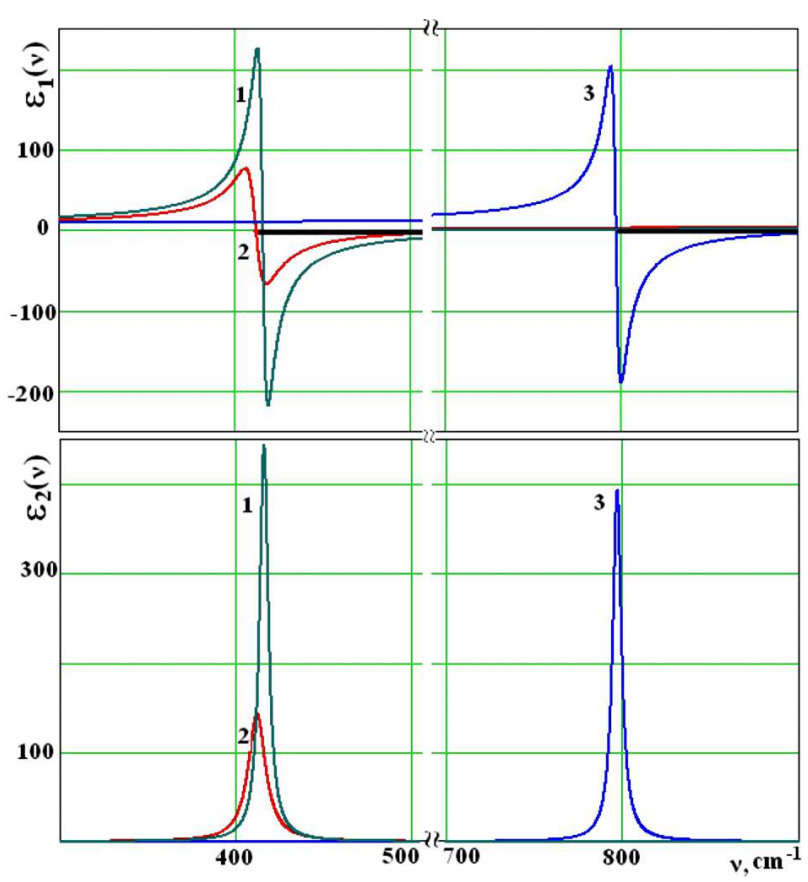

Fig. 5. Frequency dependences of the real, $\varepsilon_{1}(\nu)$, and imaginary, $\varepsilon_{2}(\nu)$, parts of the dielectric permittivity for $\mathrm{MgO}(1)$, $\mathrm{ZnO}(2)$, and 6H-SiC (3) single crystals

that the increase of the plasmon frequency (the free charge carrier concentration) in the $\mathrm{Mg}_{x} \mathrm{Zn}_{1-x} \mathrm{O}$ film deposited onto the strongly doped $6 \mathrm{H}-\mathrm{SiC}$ substrate in the case where the parameters $\nu_{p}=\gamma_{p}$ vary from 100 to $1000 \mathrm{~cm}^{-1}$ modifies the $R(\nu)$ spectrum in the whole IR range. In its low-frequency section, which is practically formed by the parameters of the $\mathrm{Mg}_{x} \mathrm{Zn}_{1-x} \mathrm{O}$ film, the growth of $R(\nu)$ by $25 \%$ takes place. At the same time, in the high-frequency section, where the spectrum is formed by the substrate made of an optically anisotropic semiconductor, the $R(\nu)$ spectrum decreases by $20 \%$ in the range of "residual rays" and increases by $35 \%$ in the interval from $1000 \mathrm{~cm}^{-1}$ (curve 1) to $1200 \mathrm{~cm}^{-1}$ (curve $5)$. The change of $R(\nu)$ is maximum at the frequencies $\nu \approx \nu_{L}$. This fact testifies to the necessity to account for the plasmon-phonon interaction in the film and the substrate, when simulating the IR reflectance spectra and carrying out the dispersion analysis of the $\mathrm{Mg}_{x} \mathrm{Zn}_{1-x} \mathrm{O} / 6 \mathrm{H}-\mathrm{SiC}$ structure.

While studying the optical and electrophysical properties of thin doped (non-doped) films on doped (non-doped) substrates, in addition to the method of external IR reflection spectroscopy, the method of polariton spectroscopy [19] is also applied. It provides information not only about the physical and chemical properties of the film, but also the parameters of the substrate and the quality of its surface treatment.

The data obtained above made it possible to perform complex studies concerning the capability of exciting surface polaritons in the $\mathrm{Mg}_{x} \mathrm{Zn}_{1-x} \mathrm{O} / 6 \mathrm{H}-\mathrm{SiC}$ structure. The self-consistent $\mathrm{Mg}_{x} \mathrm{Zn}_{1-x} \mathrm{O}$ and $6 \mathrm{H}-$ $\mathrm{SiC}$ parameters (see Tables 1 and 2) were used to calculate the ATR spectra. As for the plasmon damping coefficients in the $\mathrm{Mg}_{x} \mathrm{Zn}_{1-x} \mathrm{O}$ films, all corresponding curves were calculated in the case $\nu_{p}=\gamma_{p}$. The damping parameter $\gamma_{f}$ for the phonon subsystem of $6 \mathrm{H}-\mathrm{SiC}$ was taken to equal $3 \mathrm{~cm}^{-1}$.

Surface polaritons in polar crystals are excited only in the so-called surface-active media. The latter have a negative dielectric constant in a certain frequency interval of electromagnetic waves [19].

Figure 5 illustrates the real, $\varepsilon_{1}(\nu)$, and imaginary, $\varepsilon_{2}(\nu)$, parts of the dielectric permittivity for $\mathrm{MgO}$ (cutve 1), $\mathrm{ZnO}$ (curve 2), and 6H-SiC (curve 3) single crystals. They were calculated according to the following mathematical expressions [19]:

$\varepsilon_{1}(\nu)=\varepsilon_{\infty 1}+\frac{\nu^{2}-\nu_{L 1}^{2}}{\left(\nu^{2}-\nu_{T 1}^{2}\right)+i \nu \gamma_{f 1}}$,
$\varepsilon_{2}(\nu)=\varepsilon_{\infty 2}+\frac{\nu^{2}-\nu_{L 2}^{2}}{\left(\nu^{2}-\nu_{T 2}^{2}\right)+i \nu \gamma_{f 2}}$.

One can see that there are sections along the abscissa axis $-\left[\nu_{T O 1}, \nu_{L O 1}\right],\left[\nu_{T O 2}, \nu_{L O 2}\right]$, and $\left[\nu_{T O 3}, \nu_{L O 3}\right]$ (bold lines) - where the real part of the dielectric permittivity is non-positive, $\varepsilon_{1}(\nu) \leq 0$. According to work [19], those frequency "windows" testify that surface phonon and plasmon-phonon polaritons can exist in optically isotropic crystals and the structures fabricated on their basis exactly in those sections. The limiting values of the indicated frequencies are determined from the condition [19]

$\varepsilon_{1}\left(\nu_{s}\right)+\varepsilon_{2}\left(\nu_{s}\right)=0$.

According to Fig. 5, in the case of $\mathrm{MgO}, \mathrm{ZnO}$, and $6 \mathrm{H}-\mathrm{SiC}$ single crystals, the sections of anomalous dispersion are located in different frequency ranges. Each medium is surface-active in the corresponding section $\left(412-590 \mathrm{~cm}^{-1}\right.$ for $\mathrm{ZnO}, 416-$ $738 \mathrm{~cm}^{-1}$ for $\mathrm{MgO}$, and $797-970 \mathrm{~cm}^{-1}$ for $6 \mathrm{H}-\mathrm{SiC}$ ), whereas the medium on the other side of interface

ISSN 2071-0194. Ukr. J. Phys. 2020. Vol. 65, No. 2 
(air) is surface-inactive. Therefore, the following order is valid for the frequencies of the transverse and longitudinal optical phonons in the analyzed system:

$\left(\nu_{T O 1}, \nu_{T O 2}\right)<\nu_{L O 1}<\nu_{L O 2}<\nu_{T O 3}<\nu_{L O 3}$,

where the subscripts 1,2 , and 3 characterize the film and the substrate, respectively.

The ATR spectra are calculated using the mathematical editor MathCAD and according to formulas that account for the interaction of IR radiation with the phonon and plasmon subsystems in the film and the "semiinfinite" semiconductor or dielectric substrate in the case $E \perp c$ :

$R(\nu, \varphi)=\left(\left\lfloor\frac{1+i P(\nu, \varphi)}{1-i P(\nu, \varphi)}\right)^{2}\right.$,

where

$P(\nu, \varphi)=\frac{\beta_{2}(\nu, \varphi)}{\beta_{1}(\nu, \varphi)} \times$

$\times \frac{\beta_{3}(\nu, \varphi) A(\nu, \varphi)+\beta_{2}(\nu, \varphi) \tanh \left(k_{2}(\nu, \varphi) \times 2 \pi d\right)}{\beta_{2}(\nu, \varphi)+\beta_{3}(\nu, \varphi) A(\nu, \varphi) \tanh \left(k_{2}(\nu, \varphi) \times 2 \pi d\right)}$,

$A(\nu, \varphi)=\frac{\beta_{4}(\nu, \varphi)+\beta_{3}(\nu, \varphi) \tanh \left(k_{3}(\nu, \varphi) \times 2 \pi d\right)}{\beta_{3}(\nu, \varphi)+\beta_{4}(\nu, \varphi) \tanh \left(k_{3}(\nu, \varphi) \times 2 \pi \nu\right)}$,

$\beta_{i}(\nu, \varphi)=\frac{\varepsilon_{i}}{k_{i}(\nu, \varphi)} \quad(i=1,2,3,4)$,

$k_{1}(\nu, \varphi)=\sqrt{\varepsilon_{1}} \cos (\varphi)$,

$k_{i}(\nu, \varphi)=\sqrt{\left(k_{x}(\nu, \varphi)\right)^{2}-\varepsilon_{i}} \quad(i=2,3,4)$,

$k_{x}(\nu, \varphi)=\sqrt{\varepsilon_{1}} \sin (\varphi)$.

Here, the subscripts 1 to 4 correspond to the ATR prism, vacuum gap with thickness $d_{g}$, semiconductor (dielectric) film with thickness $d_{\text {film }}$, and "semiinfinite" substrate, respectively. The dielectric permittivity of the film, $\varepsilon_{3}(\nu)$, additively accounts for the contributions of active optical phonons, $\nu_{T}$, and plasmons, $\nu_{p}$, in thin heavily doped films.

In Fig. 6, the ATR spectra calculated for $\mathrm{ZnO}$ (curves 1 and 2), $\mathrm{MgO}$ (curves 3 and 4 ), and $6 \mathrm{H}-\mathrm{SiC}$ (curves 5 and 6 ) single crystals and the charge carrier concentration $n \approx 10^{16} \mathrm{~cm}^{-3}$ in $\mathrm{ZnO}$ and $6 \mathrm{H}-\mathrm{SiC}$ are depicted. The spectra are obtained by the scanning over the frequency $\nu$ at fixed incidence angles $\alpha$ of IR radiation in the ATR prism. In particular, the scanning was performed at the angles $\alpha=35^{\circ}$ (curves 1, 3, 5) and $\alpha=40^{\circ}$ (curves 2, 4, 6) and various values of the gap $d$ between the ATR prism and the investigated specimen. In the cases of $\mathrm{MgO}$ and $\mathrm{ZnO}, d_{g}=9.5 \mu \mathrm{m}$ at $\alpha=35^{\circ}$, and $d_{g}=7.5 \mu \mathrm{m}$

ISSN 2071-0194. Ukr. J. Phys. 2020. Vol. 65, No. 2

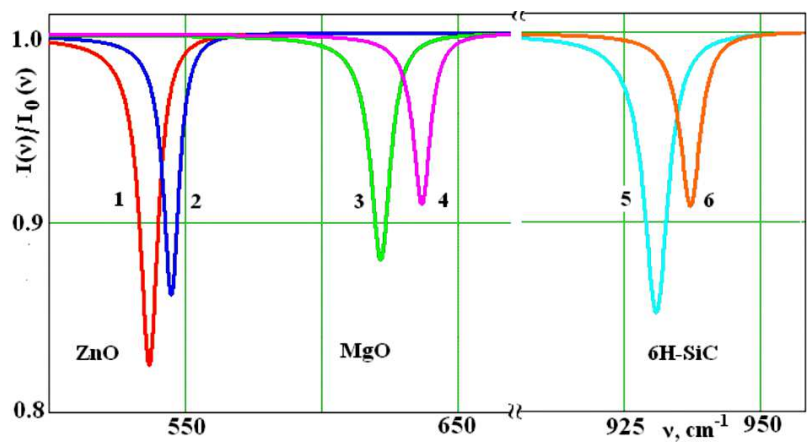

Fig. 6. ATR spectra for $\mathrm{ZnO}, \mathrm{MgO}$, and $6 \mathrm{H}-\mathrm{SiC}$

at $\alpha=40^{\circ}$. For $6 \mathrm{H}-\mathrm{SiC}$ single crystals, $d_{g}=4.8 \mu \mathrm{m}$ at $\alpha=5.8^{\circ}$, and the frequencies of the minima in the ATR spectra were $\nu_{1-6}=537,545,621,637$, 931, and $937 \mathrm{~cm}^{-1}$, which corresponded to the coefficients $R\left(\nu_{1-6}\right)=0.82,0.86,0.88,0.91,0.85,0.91$, respectively.

The mathematical simulation of ATR spectra showed that if the gap between the prism and the specimen decreases, the minimum of the ATR spectrum broadens and shifts into the high-frequency region. In addition, the ATR spectra demonstrate a reduction of the coefficient $I(\nu) / I_{0}(\nu)$, in comparison with $100 \%$, at the given surface-polariton frequency. If the gap between the ATR prism and the crystal is not large enough (within the light wavelength), a backward transformation of the SP into a light wave, the so-called radiation decay of the SP, occurs, which distorts the research results [19]. Therefore, a gap $d_{g}$ was formed by means of spacers between the ATR prism and the examined crystal. The gap was gradually increased, and the reflection signal $I(\nu) / I_{0}(\nu)$ was monitored until the frequency position of the minimum was shifted, and the intensity of absorbed wave did not exceed $20 \%$. This was the sought gap value. The inequality $I(\nu) / I_{0}(\nu) \geq 80 \%$ was selected as a criterion of the absence of a radiation influence on the ATR spectrum.

In Fig. 7, the ATR spectra $I(\nu) / \mathrm{I}_{0}(\nu)$ calculated for the $\mathrm{Mg}_{x} \mathrm{Zn}_{1-x} \mathrm{O} / 6 \mathrm{H}-\mathrm{SiC}$ structure $\left(n=10^{16} \mathrm{~cm}^{-3}\right)$ with the air gap $d_{s}=4 \mu \mathrm{m}$ and the angles $\alpha=30^{\circ}$ (curve 1) and $33^{\circ}$ (curve 2) are shown. The calculation was carried out according to formulas (5) for the geometry $E \perp c$. The air gap between the ATR prism and the $\mathrm{Mg}_{x} \mathrm{Zn}_{1-x} \mathrm{O} / 6 \mathrm{H}-\mathrm{SiC}$ specimen was changed until there appeared a minimum in the ATR spectra [2]. 


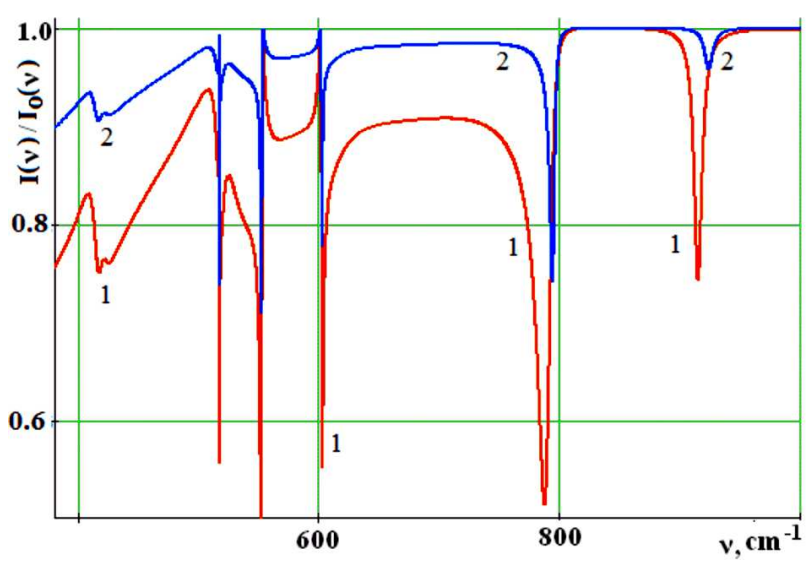

Fig. 7. ATR spectra for the $\mathrm{Mg}_{x} \mathrm{Zn}_{1-x} \mathrm{O} / 6 \mathrm{H}-\mathrm{SiC}$ structure with $d_{g}=4 \mu \mathrm{m}$ for various $\varphi=30^{\circ}$ and $33^{\circ}$
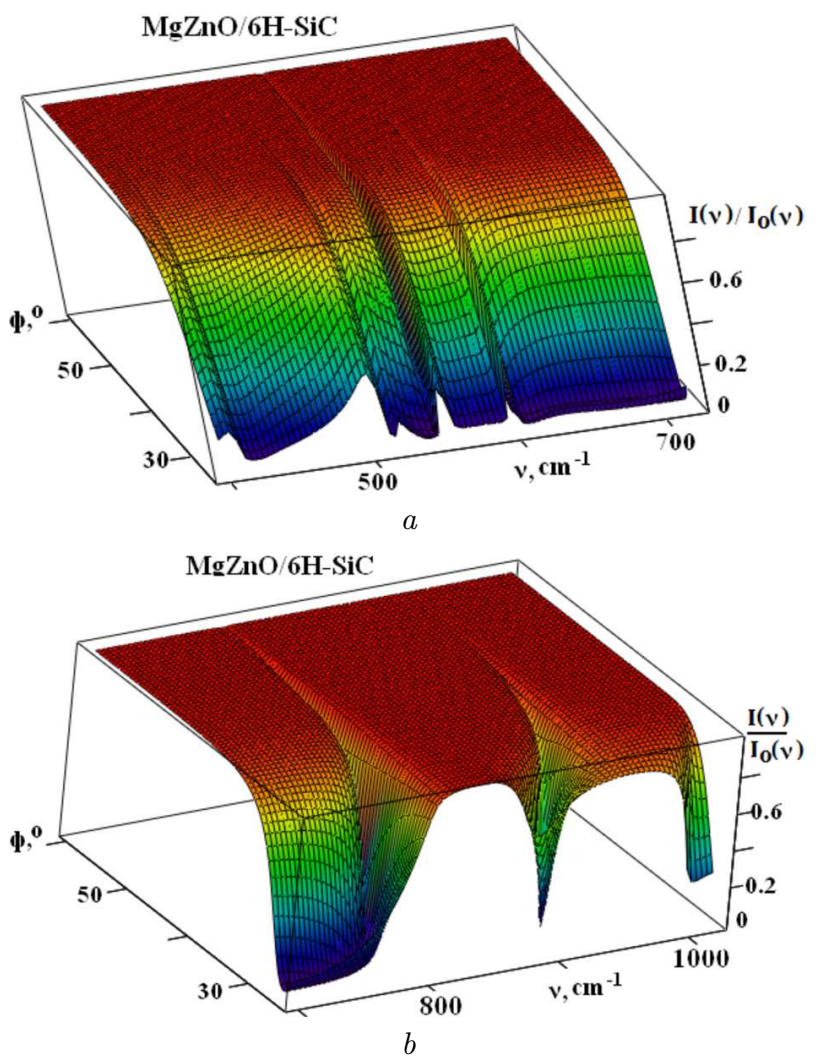

Fig. 8. Surface of modified ATR for the $\mathrm{Mg}_{x} \mathrm{Zn}_{1-x} \mathrm{O}$ film on the optically anisotropic $6 \mathrm{H}-\mathrm{SiC}$ substrate in the orientation $E \perp c$

There are two interfaces in the $\mathrm{Mg}_{x} \mathrm{Zn}_{1-x} \mathrm{O} / 6 \mathrm{H}-$ SiC system: air $/ \mathrm{Mg}_{x} \mathrm{Zn}_{1-x} \mathrm{O}$ film and $\mathrm{Mg}_{x} \mathrm{Zn}_{1-x} \mathrm{O}$ film $/ 6 \mathrm{H}-\mathrm{SiC}$ substrate. Unlike $\mathrm{Mg}_{x} \mathrm{Zn}_{1-x} \mathrm{O}$, the plasmon subsystem in $6 \mathrm{H}-\mathrm{SiC}$ is characterized by a strong anisotropy of its properties [44], whereas the $\mathrm{Mg}_{x} \mathrm{Zn}_{1-x} \mathrm{O}$ compounds have the optical anisotropy of phonons. The $\mathrm{Mg}_{x} \mathrm{Zn}_{1-x} \mathrm{O} / 6 \mathrm{H}-\mathrm{SiC}$ structure includes two surfactants. An analysis showed that there can be three SPs at the film-air interface and two more SPs at the interface between the film and the substrate.

The assumption that it is surface polaritons that are excited in the $\mathrm{Mg}_{x} \mathrm{Zn}_{1-x} \mathrm{O} / 6 \mathrm{H}-\mathrm{SiC}$ system is confirmed by the presence of minima in the ATR spectra for the only $p$-polarized IR radiation and only in the frequency interval, where the dielectric permittivity is negative (this is the interval between the frequencies of transverse and longitudinal optical phonons). Furthermore, the minimum of the ATR spectrum shifts toward the high-frequency side, if the angle of light incidence in the ATR prism increases or the absorption intensity decreases, provided a fixed gap between the ATR prism and the $\mathrm{Mg}_{x} \mathrm{Zn}_{1-x} \mathrm{O} / 6 \mathrm{H}-\mathrm{SiC}$ system [40-42]. Another confirmation of the SP existence in the $\mathrm{Mg}_{x} \mathrm{Zn}_{1-x} \mathrm{O} / 6 \mathrm{H}-\mathrm{SiCMg}_{x} \mathrm{Zn}_{1-x} \mathrm{O} / 6 \mathrm{H}-\mathrm{SiC}$ structure is the fact that the growth of the incidence angle gives rise to a shift of the minimum in the ATR spectra toward higher frequencies (Fig. 7) and a reduction of the spectrum "half-width".

Of course, more accurate data can be obtained by constructing the so-called ATR surface. The ATR surface $I(\nu) / I_{0}(\nu)$ is a three-dimensional representation of the transmittance of the researched system depending on the radiation frequency and the incidence angle. In the absence of a radiation interaction with the structure surface, we have $I(\nu) / I_{0}(\nu)=1$, so that the ATR surface is flat in this case. But if surface polaritons are excited in the film or the substrate, there appear a number of "clefts" on the $I(\nu) / I_{0}(\nu)$ surface (Fig. 8). The depths of the "clefts" depend on system's parameters such as the size of the gap between the ATR semicylinder and the specimen, the radiation frequency, and so forth. The calculations showed that if the film thickness varies from 0.001 to $0.05 \mu \mathrm{m}$, almost no manifestations are observed in the ATR spectrum. However, a further increase of the $\mathrm{Mg}_{x} \mathrm{Zn}_{1-x} \mathrm{O}$ film thickness at constant parameters of the phonon and plasmon subsystems considerably deforms the ATR spectrum in the range of "residual rays" of the $\mathrm{Mg}_{x} \mathrm{Zn}_{1-x} \mathrm{O}$ film and the substrate. At $d_{\text {film }}>0.1 \mu \mathrm{m}$, the minima in the excitation range of SPs in the $\mathrm{Mg}_{x} \mathrm{Zn}_{1-x} \mathrm{O}$ film become closer to each other. The results of a mathematical 
experiment showed that if $d_{\text {film }}=10 \mu \mathrm{m}$, the highand low-frequency minima in the ATR spectra coincide both with each other and with the data for zinc oxide single crystals. In the $300-800-\mathrm{cm}^{-1}$ interval of ATR spectra, there is only one minimum for every incidence angle of IR radiation in the ATR prism. The growth of the electron concentration and mobility in the $\mathrm{Mg}_{x} \mathrm{Zn}_{1-x} \mathrm{O}$ film leads to a significant deformation of the ATR spectrum in the range of "residual rays" of the $\mathrm{Mg}_{x} \mathrm{Zn}_{1-x} \mathrm{O} / 6 \mathrm{H}-\mathrm{SiC}$ structure provided that the film thickness is constant.

Surface oscillations in the film and the substrate are characterized by the amplitude damping when removing from the surface, and the energy spectrum dependence on the dielectric permittivity of the external medium. In particular, there appears an interdependence of surface excitations in two media, which is partially responsible for the emergence of mixed plasmon-phonon oscillations that damp on the both sides of the interface (Figs. 7 and 8).

If the film thickness is much larger than the radiation wavelength, surface electromagnetic waves propagate along the both surfaces and do not interact with each other.

Figure $8, b$ clearly demonstrates that the frequencies of the minima in the ATR spectra of SPs in the $6 \mathrm{H}-\mathrm{SiC}$ substrate grow from 956 to $960 \mathrm{~cm}^{-1}$, when the incidence angle decreases from $40^{\circ}$ to $25^{\circ}$. Then the frequencies of the spectral minima shift from 980 to $1000 \mathrm{~cm}^{-1}$, as the incidence angle increases to $30^{\circ}$. If the optical phonon damping is taken into account, there emerges a second "cleft" on the ATR surface $R(\nu)$ separated from the first one by a "pass" located at frequencies that can be experimentally registered, when recording the ATR spectra of SPs by scanning over the angles.

\section{Conclusions}

To summarize, in this work, using the method of external reflection IR spectroscopy, the optical characteristics of thin films of ternary $\mathrm{Mg}_{x} \mathrm{Zn}_{1-x} \mathrm{O}$ compounds on the $6 \mathrm{H}-\mathrm{SiC}$ semiconductor substrate are obtained in the range of "residual rays" of the film and the substrate. It is shown that the variations of the film thickness and the $\mathrm{Mg}$ content substantially deform the reflection spectrum in the range of "residual rays" of the film and the substrate and reduce the reflectance of the structure. The computer simulation of the IR spectra allowed us to model the IR reflection and ATR spectra for the $\mathrm{Mg}_{x} \mathrm{Zn}_{1-x} \mathrm{O} / 6 \mathrm{H}-\mathrm{SiC}$ structure with $x=0.2$ in the case of $E \perp c$ orientation.

It is found that the $\mathrm{Mg}_{x} \mathrm{Zn}_{1-x} \mathrm{O} / 6 \mathrm{H}-\mathrm{SiC}$ structures can be well simulated with the help of self-consistent parameters obtained for single crystalline magnesium oxide, zinc oxide, and silicon carbide (the $6 \mathrm{H}$ polytype) (see Tables 1 and 2 ) in the case of the $E \perp c$ orientation. This fact confirms the potential of the nondestructive IR spectroscopy method for the determination of optical characteristics in ternary-compound films, as well as their electrophysical properties.

Thus, the following conclusions can be drawn:

- the semiconductor structure $\mathrm{Mg}_{x} \mathrm{Zn}_{1-x} \mathrm{O} / 6 \mathrm{H}$ $\mathrm{SiC}$ has frequency "windows" in the range of "residual rays" of the $\mathrm{Mg}_{x} \mathrm{Zn}_{1-x} \mathrm{O}$ film and the $6 \mathrm{H}-\mathrm{SiC}$ substrate, where the excitation and propagation of surface polaritons are possible;

- with the help of a mathematical experiment, a possibility to experimentally study surface polaritons in the $\mathrm{Mg}_{x} \mathrm{Zn}_{1-x} \mathrm{O} / 6 \mathrm{H}-\mathrm{SiC}$ system with fixed film thicknesses $(0.1-1 \mu \mathrm{m})$ using the ATR method - either by scanning over the frequency at fixed incidence angles or by scanning over the incidence angle at fixed frequencies - is demonstrated.

This work was supported by Ministry of Education and Sciences of Ukraine via the project No. 89452.

1. A. Janotti, Ch.G. Van de Walle. Fundamentals of zinc oxide as a semiconductor. Rep. Prog. Phys. 72, 126501 (2009).

2. A. Ohtomo, M. Kawasaki, T. Koida, K. Masubuchi, H. Koinuma, Y. Sakurai, Y. Yoshida, T. Yasuda, Y. Segawa. $\mathrm{Mg}_{x} \mathrm{Zn}_{1-x} \mathrm{O}$ as a II-VI widegap semiconductor alloy. Appl. Phys. Lett. 71, 2466 (1998).

3. A. Ohtomo, K. Tamura, M. Kawasaki, T. Makino, Y. Segawa, Z.K. Tang, L.G.K. Wong, Y. Matsumoto, H. Koinuma. Room-temperature stimulated emission of excitons in $\mathrm{ZnO} /(\mathrm{Mg}, \mathrm{Zn}) \mathrm{O}$ superlattices. Appl. Phys. Lett. 77, 2204 (2000).

4. Y. Jin, B. Zhang, Y. Shuming, Y. Wang, J. Chen, H. Zhang, C. Huang, C. Cao, H. Cao, R.P.H. Chang. Room temperature UV emission of $\mathrm{Mg}_{x} \mathrm{Zn}_{1-x} \mathrm{O}$ films. Solid State Commun. 119, 409 (2001).

5. T. Makino, Y. Segawa, A. Ohtomo, K. Tamura, H. Koinuma. Band gap engineering based on $\mathrm{Mg}_{x} \mathrm{Zn}_{1-x} \mathrm{O}$ ternary alloy films. Appl. Phys. Lett. 78, 1237 (2001).

6. Th. Gruber, C. Kirchner, R. Kling, F. Reuss, A. Waag. Zn$\mathrm{MgO}$ epilayers and $\mathrm{ZnO}-\mathrm{ZnMgO}$ quantum wells for optoelectronic applications in the blue and UV spectral region. Appl. Phys. Lett. 84, 5359 (2004). 
7. Surface Acoustic Waves. Edited by A.A. Oliner (SpringerVerlag, 1978).

8. A.I. Morozov, V.V. Proklov, B.A. Stankovskii. Piezoelectric Transducers for Electronic Devices (Radio i Svyaz', 1981) (in Russian).

9. K.L. Chopra, S.R. Das. Thin Film Solar Cells (Springer, 1983).

10. Ü. Özgür, Ya.I. Alivov, C. Liu, A. Teke, M.A. Reshchikov, S. Doğan, V. Avrutin, S.-J. Cho, H. Morkoç. A comprehensive review of $\mathrm{ZnO}$ materials and devices. J. Appl. Phys. 98, 041301 (2005).

11. A.B. Djurisic, A.M.C. Ng, X.Y. Chen. ZnO nanostructures for optoelectronics: Material properties and device applications. Progr. Quant. Electron. 34, 191 (2010).

12. A. Moezzi, A.M. McDonagh, M.B. Cortie. Zinc oxide particles: Synthesis, properties and applications. Chem. Eng. J. 22, 185 (2012).

13. A.I. Yevtushenko, G.V. Lashkaryov, V.Y. Lazorenko, V.A. Karpina, V.D. Khranovskyi. ZnO detectors of ultraviolet radiation. Fiz. Khim. Tverd. Tila 9, 869 (2008) (in Ukrainian).

14. R. Scheer, H.-W. Schock. Chalcogenide Photovoltaics: Physics, Technologies, and Thin Film Devices (Wiley$\mathrm{VCH}, 2011$ ).

15. G. Shukla. $\mathrm{ZnO} / \mathrm{MgZnO} p-n$ junction light-emitting diodes fabricated on sapphire substrates by pulsed laser deposition technique. J. Phys. D 42, 075105 (2009).

16. Y. Hu, B. Cai, Z. Hu, Y. Liu, Sh. Zhang, H. Zeng, The impact of $\mathrm{Mg}$ content on the structural, electrical and optical properties of $\mathrm{MgZnO}$ alloys: A first principles study. Current Applied Physics 15 (3), 423 (2015).

17. S.P. Bharath Kasturi, V. Bangera, G.K. Shivakumar. Effect of cadmium incorporation on the properties of zinc oxide thin films. Appl. Nanoscience 8 (1-2), 187 (2018).

18. B.M. Mychalichko. General Chemistry Course: Theoretical Foundations (Znannya, 2009) (in Ukrainian).

19. Ye.F. Venger, O.V. Melnichuk, Yu.A. Pasechnyk. Spectroscopy of Residual Rays (Naukova Dumka, 2001) (in Ukrainian).

20. Ye.F. Venger, I.V. Venger, D.V. Korbutyak, N.O. Korsunska, L.Yu. Melnichuk, O.V. Melnichuk, L.Yu. Khomenkova. Surface polaritions in $\mathrm{MgZnO} / 6 \mathrm{H}-\mathrm{SiC}$ heterostructures. In Materials of the International Conference "Functional materials for innovative energy-FMIE-2019" (Kyiv, 2019), p. 4 (Y24).

21. U. Rau, D. Abou-Ras, T. Kirchartz. Advanced Characterization Techniques for Thin Film Solar Cells (Wiley-VCH, 2011).

22. N.A. Kovtun, B.T. Boiko, G.S. Khripunov, V.R. Kopach. Electrical properties of transparent polycrystalline $\mathrm{ZnO}$ : Al films obtained by magnetron sputtering. Vopr. At. Nauki Tekhn. No. 10, 75 (1999).

23. N.V. Romanova. General and Inorganic Chemistry (VTF Perun, 1998) (in Ukrainian).
24. P.I. Baranskii, V.P. Klochkov, I.V. Potykevich, Semiconductor Electronics. Reference Book (Naukova Dumka, 1975) (in Russian).

25. A.V. Melnichuk, Yu.A. Pasechnik. Anisotropy of electron effective masses in silicon carbide. Fiz. Tverd. Tela 34, 423 (1992) (in Russian).

26. Chunming Jin. Growth and Characterization of $Z n O$ and $\mathrm{ZnO}$-Based Alloys $M g_{x} Z n_{1-x} O$ and $M n_{x} Z n_{1-z} O$. Ph.D. Thesis (North Carolina State University, Raleigh, 2003).

27. I. Markevich, T. Stara, L. Khomenkova, V. Kushnirenko, L. Borkovska. Photoluminescence engineering in polycrystalline $\mathrm{ZnO}$ and $\mathrm{ZnO}$-based compounds. AIMS Mater. Sci. 3, 508 (2016).

28. L. Borkovska, L. Khomenkova, I. Markevich, M. Osipyonok, O. Kolomys, S. Rarata, O. Oberemok, O. Gudymenko, A. Kryvko, V. Strelchuk. The effect of high temperature annealing on the photoluminescence of $\mathrm{ZnMgO}$ alloys. Phys. Status Solidi A 215, 1800250 (2018).

29. D. Thapa, J. Huso, J. Lapp, N. Rajabi, J.L. Morrison, M.D. McCluskey, L. Bergman. Thermal stability of ultra-wide-bandgap $\mathrm{MgZnO}$ alloys with wurtzite structure. J. Materials Science: Materials in Electronics 29 (19), 16782 (2018).

30. Z. Xi-Jian, M. Hong-Lei, L. Yu-Xiang, W. Qing-Pu, M. Jin, Z. Fu-Jian, X. Hong-Di. The optical properties of $\mathrm{Mg}_{x} \mathrm{Zn}_{1-x} \mathrm{O}$ thin films. Chin. Phys. 15, 2385 (2006).

31. K. Hoggas, C. Nouveau, A. Djelloul, M. Bououdina. Structural, microstructural, and optical properties of $\mathrm{Zn}_{1-x} \mathrm{Mg}_{x} \mathrm{O}$ thin films grown onto glass substrate by ultrasonic spray pyrolysis. Appl. Phys. A 120, 745 (2015).

32. P.A. Ivanov, V.E. Chelnokov. Semiconductor silicon carbide: Technology and devices. Fiz. Tekh. Poluprovodn. 29, 1921 (1995) (in Russian).

33. E.F. Venger, A.V. Melnichuk, L.Ju. Melnichuk, Ju.A. Pasechnik. Anisotropy of the $\mathrm{ZnO}$ single crystal reflectivity in the region of residual rays. Phys. Status Solidi $B \mathbf{1 8 8}$, 823 (1995).

34. H. Karakachian, M. Kazan. Dependence of surface plasmon-phonon-polariton in $4 \mathrm{H}-\mathrm{SiC}$ on free carrier concentration. J. Appl. Phys. 121, 093103 (2017).

35. Ye.F. Venger, A.I. Yevtushenko, D.V. Korbutyak, L.Yu. Melnichuk, O.V. Melnichuk. Investigation of magnesium oxide by IR spectroscopy methods. In Physical and Mathematical Notes. Collection of Scientific Works No. 53 (2010) (in Ukrainian).

36. O. Melnichuk, L. Melnichuk, B. Tsykaniuk, Z. Tsybrii, P. Lytvyn, C. Guillaume, X. Portier, V. Strelchuk, Ye. Venger, L. Khomenkova, N. Korsunska. Investigation of undoped and Tb-doped $\mathrm{ZnO}$ films on $\mathrm{Al}_{2} \mathrm{O}_{3}$ substrate by infrared reflection method. Thin Solid Films 673, 136 (2019).

37. N. Korsunska, L. Borkovska, Yu. Polischuk, O. Kolomys, P. Lytvyn, I. Markevich, V. Strelchuk, V. Kladko, O. Melnichuk, L. Melnichuk, L. Khomenkova, C. Guillaume, $\mathrm{X}$. Portier. Photoluminescence, conductivity and structural study of terbium doped $\mathrm{ZnO}$ films grown on different substrates. Mater. Sci. Semicond. Process. 94, 51 (2019).

ISSN 2071-0194. Ukr. J. Phys. 2020. Vol. 65, No. 2 
38. O.V. Melnichuk, L.Yu. Melnichuk, N.O. Korsunska, L.Yu. Khomenkova, Ye. Venger. Optical and electrical properties of $\mathrm{Tb}-\mathrm{ZnO} / \mathrm{SiO}_{2}$ structure in the infrared spectral interval. Ukr. J. Phys. 64, 431 (2019).

39. E.A. Vinogradov, N.N. Novikova, V.A. Yakovlev. Phononpolariton near-field spectroscopy as a method for studying the optical properties of nanofilms. Usp. Fiz. Nauk 184, 653 (2014) (in Russian).

40. A.V. Melnichuk. The study of surface plasmon-phonon polaritons in SiC-6H single crystals using the ATR method. Poverkhnost Fiz. Khim. Mekhan. 7, 76 (1998) (in Russian).

41. Ye.F. Venger, L.Yu. Melnichuk, O.V. Melnichuk, Yu.A. Pasichnyk, O.I. Sukhenko. Surface plasmon-phonon polaritons of silicon carbide. Ukr. Fiz. Zh. 43, 598 (1998) (in Ukrainian).

42. A.V. Melnichuk, Yu.A. Pasechnik. Anisotropy effect on the dispersion of surface plasmon-phonon polaritons of silicon carbide. Fiz. Tverd. Tela 40, 636 (1998) (in Russian).

43. M.A. Ilyin, F.F. Kukharskii, E.P. Rashevskaya, V.K. Subashiev. Effective masses of free electrons in silicon carbide. Fiz. Tverd. Tela 13, 2478 (1971) (in Russian).

44. E.F. Venger, I.V. Venger, N.O. Korsunska, L.Yu. Melnichuk, O.V. Melnichuk, L.Yu. Khomenkova. Optical properties of ternary alloys $\mathrm{MgZnO}$ in infrared spectrum. Semicond. Phys. Quant. Electr. Optoelectr. 21, 417 (2018).

45. J. Chen, W.Z. Shen. Long-wavelength optical phonon properties of ternary MgZnO thin films. Appl. Phys. Lett. 83, 2154 (2003).

Received 28.08.19.

Translated from Ukrainian by O.I. Voitenko
О.В. Мелъничук, Л.Ю. Мелъничук,

Н.О. Корсунсъка, Л.Ю. Хоменкова,

Є.Ф.Венгер, І.В. Венгер

ФОНОН-ПОлЯРИТОНні

ЗБУДЖЕННЯ В СТРУКТУРАХ MgZnO/6H-SiC

Р е з ю м е

Для тонких плівок $\mathrm{Mg}_{x} \mathrm{Zn}_{1-x} \mathrm{O}$, нанесених на оптичноанізотропних підкладках $6 \mathrm{H}-\mathrm{SiC}$, вперше було змодельовано спектри зовнішнього інфрачервоного відбивання в області "залишкових променів" плівки та підкладки за орієнтації електричного поля $E \perp c$ з використанням взаємно узгоджених параметрів, отриманих раніше для монокристалів оксиду магнію, оксиду цинку та карбіду кремнію. Показано, що зміни товщини плівки і вмісту $\mathrm{Mg}$ суттєво деформують спектр відбивання та зменшують відбивальну здатність $R(\nu)$. Використовуючи співвідношення КрамерсаКроніга, визначено спектральні області, де відбивальна здатність є чутливою до зміни товщини плівки, ступеня легування плівки та підкладки для структури $\mathrm{Mg}_{x} \mathrm{Zn}_{1-x} \mathrm{O} / 6 \mathrm{H}-$ $\mathrm{SiC}$. Основну увагу приділено аналізу даних для значення $x=0,2$. Уперше теоретично продемонстровано існування поверхневих поляритонів для таких структур та побудовано поверхню порушеного повного внутрішнього відбивання $I(\nu) / I_{0}(\nu)$, яка являє собою тривимірне представлення коефіцієнта пропускання зазначеної вище структури і залежить від частоти випромінювання і кута падіння. Продемонстровано можливість досліджень резонансної взаємодії оптичних фононів та плазмонів плівки та підкладки. 